УДК 33

DOI $10.21661 / \mathrm{r}-115141$

\title{
В.В. Курочкин
}

\section{ФИНАНСИРОВАНИЕ ФИЗИЧЕСКОЙ КУЛЬТУРЫ И СПОРТА В РОССИИ}

Аннотация: по мнению автора, в современных условиях спорт становится одним из приоритетных направлений социальной политики, реализация которого решает не только задачи оздоровления нации, но и формирует имидж государства на международной арене. Это обуславливает возростее внимание исследователей к сочиокультурным, физическим и экономическим факторам развития спортивной отрасли. Предполагается, что их реализация возможна только при наличии достаточного объема финансовых ресурсов, их оптимального распределения на массовый спорт, физическую культуру и спорт высоких достижений. В статье также рассматриваются организачионные основы, источники и порядок финансирования спортивных организаций, особенности мобилизащии средств, характерные для России. На материалах целевой программы «Развитие физической культуры и спорта в Российской Федераџии на 2016-2020 г2.» показана решающая роль бюджетных ассигнований, формы их использования.

Ключевые слова: модели, субъекты финансирования, объекты финансирования, федеральный бюджет, региональные бюджеты, источники финансирования, цены, ценообразование, спортивная отрасль.

\section{V.V.Kurochkin}

\section{FINANCING OF PHYSICAL CULTURE AND SPORTS IN RUSSIA}

Abstract: according to the author in modern terms, sport becomes one of the priority directions of social policy, the implementation of which not only solves problems of improvement of the nation, but also forms the image of the state in the international arena. This leads to increased attention of researchers to the social, cultural, physical and economic factors of the development of the sports industry. However, it is clear 
that their implementation is possible only if sufficient financial resources, their optimal distribution on mass sport, physical culture and sport of high achievements. The article also examines the organizational framework, sources and order of financing of sports organizations, particularly the mobilization of resources specific to Russia. On the materials of the target program «Development of physical culture and sports in the Russian Federation for 2016-2020» it is shown the decisive role of budgetary appropriations, the forms of their use.

Keywords: models, subjects of financing, objects of financing, Federal budget, regional budgets, sources of Finance, prices, pricing, sport industry.

В современном мире роль и значение спорта в экономической и социальнополитической жизни общества значительно возрастает как в национальном, так и мировом масштабе. Роль того или иного государства на международной арене определяется, наряду с традиционными факторами, уровнем развития и достижениями национального спорта.

В этой связи существенно возрос научный интерес к исследованию факторов, определяющих спортивные достижения, включая такие как наличие и состояние спортивных рынков, правовые отношения, государственное регулирование, сочетание индивидуальных и коллективных интересов, маркетинг и дизайн соревнований и многие другие. Вместе с тем очевидно, что среди этого разнообразного множества первостепенное значение имеет экономическое обеспечение спорта, наличие и достаточность источников финансирования.

По имеющимся оценкам доходы спорта как сферы экономической деятельности составляют порядка 150 млрд долл., формируя 0,1\% мирового ВВП. В развитых странах Европы и Америки доля спорта в ВВП достигает 3\%. Например, в ЕС вклад спорта в ВВП вполне сравним с вкладом таких отраслей федерального сектора экономики как сельское хозяйство, лесоводство и рыболовство. В частности, на реализацию федеральной целевой программы «Развитие физической культуры и спорта в Российской Федерации на 2016-2020 годы» будет мобилизовано по последним данным 94,33 млрд руб. (Программа предусматривала 
92,8 млрд руб.), в том числе за счет федерального бюджета - 72,5 млрд руб., 770 тыс. руб., из средств бюджетов субъектов РФ - 15,9 млрд руб. [1].

В России данные показатели скромнее. Вместе с тем принятые за последнее время решения предполагают существенное увеличение финансирования физической культуры и спорта.

В дальнейшем президент РФ поручил Правительству дополнить федеральную Программу подпрограммой «Развитие футбола в РФ», предусмотрев в ней меры по развитию инфраструктуры футбола, лимиты соответствующих бюджетных обязательств и нормативы обеспеченности населения такой инфраструктурой.

Также проект предусматривает капитальные вложения из федерального бюджета на реконструкцию объектов спортивной инфраструктуры Крымского федерального округа в размере 4,5 млрд руб. и на строительство и реконструкцию инфраструктуры федеральных спортивно-тренировочных центров для подготовки спортсменов сборных команд 14,6 млрд руб.

В этой связи вопросы бесперебойного финансирования, формирования оптимальной структуры расходов, эффективного контроля за целевым использованием средств приобретают первостепенное значение.

Мировая практика выработала две модели финансирования спорта - американскую и европейскую. Первая предполагает отсутствие бюджетного финансирования и в тоже время наличие разнообразных налоговых льгот для субъектов, осуществляющих инвестиции в спортивную отрасль. Европейская модель основывается на сочетании этих двух источников. Именно эта модель характерна для России. Поэтому в общем объеме финансирования программы «Развитие физической культуры и спорта в РФ на 2016-2020 гг.» на федеральный бюджет приходится почти $80 \%$, на бюджеты субъектов РФ - $17 \%$ [2]. Определенную роль играют и местные бюджеты, осуществляя финансирование массового спорта, оказание помощи желающим заниматься спортом, обеспечение нормальной эксплуатации имеющейся инфраструктуры. 
В нашей стране финансовые ресурсы для развития физической культуры и спорта формируются за счет средств, поступающих от:

- органов государственной власти и местного самоуправления;

- профсоюзов;

- внебюджетных фондов;

- коммерческих и некоммерческих организации;

- собственных доходов спортивной отрасли.

Кроме того, финансирование физической культуры и спорта, международных спортивных, благотворительных, научных исследований проводится и за счёт средств спонсоров. По имеющимся оценкам они могут составлять до $30 \%$ всех доходов. Многие спортивные клубы и организации с целью получения доходов ведут собственную хозяйственную деятельность.

Средства федерального и региональных бюджетов выступают источником финансирования материально - технического, научно - методического, медицинского обслуживания спортивных сборных команд РФ. Важным направлением использования средств является организация и проведение межрегиональных и всероссийских мероприятий и др. Так, за счет средств федерального бюджета обеспечивается проведение XXI Чемпионата мира по футболу выделено 87,5 млрд руб., на проведение 2018г. ХХІХ Всемирной зимней Универсиады 9,5 млрд руб. [3] 2019 г. Следует отметить, что все мероприятия, проводимые сборными командами страны, финансируются за счет средств федерального бюджета.

В случае представления страны на международном уровне предусматривается прямое финансирование из федерального бюджета, поскольку речь идет об отстаивании чести государства, его экономического, политического и социального престижа.

В этом случае можно рассчитывать на пополнение бюджетов спортивных организаций на модернизацию спортивных сооружений, пополнение финансовых ресурсов для выполнения конкретных программ. 
Пополнение бюджета Национального Олимпийского Комитета может происходить также путем использования специальных инструментов финансового рынка, таких как: игры по вкладам, с дифференциацией доходов в зависимости от длительности срока вложений, различных ставок и условий.

Государственное финансирование может осуществляться в форме: субсидий, как адресная поддержка определённых программ, в форме полного или частичного освобождения от налогов, в виде предоставления ассигнований на поддержку отдельного спортсмена.

В обеспечении развития профессионального спорта принимают участия также общественные организации (профсоюзы) и частные коммерческие структуры.

Условия рыночной экономики, недостаточность средств, поступающих из внешних источников обусловили активизацию видов деятельности спортивных организаций, имеющих целью получение доходов. Наиболее значимыми доходными статьями здесь выступают доходы от продажи билетов, прав медиатрансляции, сдача в аренды, доходы от продажи спортивной атрибутики. В мировой спортивной отрасли эти доходы в совокупности составляют около 65-70\% общей их суммы.

Таким образом, годовой Фонд, необходимый для эксплуатации, обслуживания, развития инфраструктуры, объем прямых затрат постоянно изменяется по кварталам, в зависимости от реальных финансовых ресурсов и доходов.

Финансовый план (баланс доходов и расходов) - неотъемлемая часть, завершающая стадия общего планирования материального обеспечения развития спорткомитетов, отдельных коллективов и клубов. В этих планах формируются источники и размеры поступления денежных средств, определяются их назначение, пути рационального использования.

Финансовый план разрабатывается на основе общего плана развития физической культуры и спорта в стране, регионе с учетом ожидаемых поступлений денежных средств. Проект финансового плана (бюджет, смета) представляют на 
рассмотрение и утверждение вышестоящим спортивным, профсоюзным, государственным организациям, после чего он считается принятым.

Существующая практика финансирования исходит, прежде всего, из соответствия мобилизованных денежных средств общему объему затрат на развитие физической культуры и спорта. Вместе с тем она подтверждает правильность и целесообразность использования физкультурными и спортивными организациями выделяемых им средств, в интересах общества, региона, государства. Этим же целям служит и финансовый контроль, осуществляемый вышестоящими организациями: ревизионными комиссиями и контрольно-ревизионными управлениями, органами финансового и бюджетного контроля.

Основные требования к разработке и утверждению финансовых планов, расходованию денежных средств, открытию кредитов и распоряжению ими являются едиными для всех физкультурных организаций, всех подразделений спортивной отрасли.

Вместе с тем наблюдаются различия в источниках формирования денежных средств и в направлениях расходования, то есть в содержании приходной и расходной части бюджетов обусловленные конкретными особенностями деятельности спортивной организации.

Существующие различия в финансировании физкультурных и спортивных организаций определяются рядом обстоятельств, в том числе спецификой управления различными звеньями и своеобразием выполняемых ими задач. Известно, что управление физкультурным движением осуществляется, во-первых, государственными организациями; во-вторых, общественными организациями и профсоюзами.

Государственное управление осуществляется через систему спорткомитетов и подразделений Министерства спорта РФ. Их деятельность финансируется из государственного бюджета и доходов принадлежащих им организаций и предприятий. Что же касается физкультурных коллективов, управляемых союзами и общественными организациями, то они финансируются как министерством, профсоюзами и частично за счет привлечения средств населения. 
Бюджет Министерства спорта разрабатывается, исходя из необходимости финансового обеспечения выполнения общего годового плана физкультурномассовой работы, календарного плана проведения спортивных мероприятий, содержания аппарата.

В приходной части бюджета определены суммы средств, выделенные для осуществления его деятельности. В расходной части - основные направления и объем расходования средств на содержание аппарата, подготовку кадров, проведение соревнований, учебно-тренировочных сборов, капитальное строительство. Определенная специфика имеется при выделении бюджетных ассигнований на содержание объектов недвижимости и капитальное строительство.

В зависимости от принадлежности и вида собственности спортивно-технические сооружения подразделяются на сооружения федерального, регионального, местного значения и принадлежащие физическим лицам, если эти сооружения приобретены или построены за их счёт. Сооружения, относящиеся к федеральному, региональному и местному имуществу не могут быть использованы как объекты другого назначения, не подлежат приватизации и коммерческой эксплуатации. Государство принимает участие в финансировании строительства, реконструкции и эксплуатации физкультурно-оздоровительных и спортивных сооружений, привлекает к их созданию и содержанию на условиях договоров и кооперации различные организации. Законодательством РФ запрещается ликвидация имеющихся сооружений, находящихся в государственной или муниципальной собственности, пока на данной территории не будут созданы равнозначные сооружения.

Следует отметить, что действующие нормативы обеспеченности жилых районов основными физкультурно-спортивными сооружениями уже не соответствуют потребностям молодого поколения и не позволяют поддерживать спортивно-оздоровительную работу на высоком уровне. Работа по привлечению широких масс населения в спорт проходит в вяло текущем режиме и ограничивается возможностями местных бюджетов, количеством и качеством сооружений, оборудования и инвентаря. Нормативы определяются органами исполнительной 
власти субъектов Российской Федерации в области физической культуры и спорта на основе общих градостроительных норм.

Специфические требования, предъявляемые к эксплуатации спортивных сооружений, не соблюдаются.

Важнейшим фактором влияния на дальнейшее развитие спортивной отрасли, особенно в части физической культуры и массового спорта является уровень заработной платы участвующих в этом процессе работников - профессионалов. Заработная плата тренеров и преподавателей физической культуры находиться на недопустимо низком уровне. Особую остроту данный вопрос приобрел сейчас на фоне запредельных гонораров и выплат отдельным спортсменам и тренерам. В этих условиях расширяется практика оплаты труда тренеров группами частных лиц заинтересованных в развитии спортивных навыков своих детей и в укреплении их здоровья.

В случае предоставления платных услуг организациями отрасли возникает вопрос о принципах формирования цен. В основном используются два варианта ценообразования: «справедливое»- предоставление возможности за незначительную плату пользоваться услугами различных физкультурно-спортивных организаций широким слоям населения; рациональное - наличие гибкой дифференциации цен позволяющей избегать перегруженности в работе физкультурноспортивных организаций в пиковые периоды времени ценообразование и др. При любом варианте продавцы спортивных услуг ориентируются на равенство цены с суммой средних издержек и получаемой прибыли.

В обоих случаях оплата физкультурно-спортивных услуг может производиться непосредственно, либо спонсорами через систему предоставляемых им в дальнейшем налоговых льгот и преференций. В зависимости от этого различают прямое и косвенное ценообразование.

Следует отметить, что в условиях рыночной экономики как при государственном, так и коммерческом методе финансирования физкультуры и спорта формирование цены на предоставляемые услуги базируется на стоимости ее производства, соотношении спроса и предложения с учетом средне взвешенной 
цены аналогичной услуги у конкурентов. Цена определяется, исходя из ее стоимости (со стороны предложения) и прибыли (со стороны спроса).

Рассмотрение только некоторых аспектов экономически спортивной отрасли показывает значимость и сложность имеющихся проблем и стоящих задач. Среди них первостепенное значение имеет создание стройной системы финансирования как спорта высших достижений, так и массового спорта. Вместе с тем в современных условиях все более актуальными становятся вопросы формирования рациональной структуры расходования средств, построение единой системы ценообразования, повышение эффективности менеджмента спортивных организаций.

\section{Список литературы}

1. Федеральная целевая программа «Развитие физической культуры и спорта в Российской Федерации на 2016-2020 годы». Постановление Правительства РФ от 21 января 2015 года. - №30.

2. Бюджет Министерства спорта Российской Федерации на 2014-2016 гг. [Электронный ресурс]. - Режим доступа: http: /www.minsport.gov.ru/activities

3. Корнеева Е.Н. Проблемы финансирования российского. Экономические науки спорта / Е.Н. Корнеева, Полежай К. - 2016. - №41-1.

Курочкин Вадим Васильевич - канд. экон. наук, профессор Департамента общественных финансов, первый заместитель декана факультета налогов и налогообложения ФГОБУ ВО «Финансовый университет при Правительстве Российской Федерации», Россия, Москва.

Kurochkin Vadim Vasilievich - candidate of economic sciences, professor of the Department of Public Finance, first associate dean of the Department of Taxes and Taxation FSBEI of HE "Financial University under the Government of the Russian Federation", Russia, Moscow. 